TABLE II.-Sequence of $\alpha T$ PIX of $H b A$ and the Suggested Sequence in Hb Stanleyville II

\begin{tabular}{|c|c|c|c|c|c|c|c|c|c|c|c|c|c|c|c|c|}
\hline $\begin{array}{l}\text { No. of Residues } \\
\text { in a-chain: }\end{array}$ & 62 & 63 & 64 & 68 & 72 & 74 & 75 & 76 & 77 & 78 & 79 & 85 & 87 & 88 & 89 & 90 \\
\hline Hb A TpIX & Val & Ala & Asp & Asn & His & Asp & Asp & Met & Pro & Asn & Ala & Asp & His & Ala & His & Lys \\
\hline $\begin{array}{ll}\text { TpIX-a } \\
\text { TpIX-b }\end{array}$ & VaI & Ala & Asp & Asn & His & Asp & Asp & Met & Pro & Lys & $\mathrm{Ala}$ & Asp & His & Ala & His & Lys \\
\hline
\end{tabular}

The amino-acid composition of $\alpha^{A}$ TpIX is 4 Asp, 2 Asn, 1 Thr, 2 Ser, 1 Pro. 7 Ala, 3 Val, 1 Met, 4 Leu, 1 Lys, 3 His.

The fact that the haemoglobin was an $\alpha$-chain variant was confirmed also by hybridization with canine haemoglobin when an aberrant $\alpha_{2}$ human $\beta_{2}$ canine was observed.

\section{Identification of the Amino-acid Substitution}

When the fingerprint (peptide chromatogram) of the purified variant was prepared it was found that the tryptic peptide No. 9 of the $\alpha$-chain ( $\alpha^{\mathrm{A}}$ TpIX) was missing (Special Plate, Fig. 2). This peptide comprises residues $62-90$ of the 141 residues of the $\alpha$-chain, of which residue 78 is an asparagine (Hill and Konigsberg, 1962). There is usually present another peptide, $\alpha^{\mathrm{A}} \mathrm{TpVIII}-\mathrm{IX}$, in which a lysine residue ( $\left.\alpha^{\mathrm{A}} \mathrm{TpVIII}\right)$ is attached to $\alpha \mathrm{TpIX}$ at its $\mathrm{N}$-terminal ; this peptide was also absent. Two new discrete peptides were noticed instead (Table I). One was in the acid region just above $\alpha^{\mathrm{A} T p I V}$ and stained positive for histidine and methionine, the other showing a more positive charge than $\alpha^{\mathrm{A}} \mathrm{T}$ IX stained positive for histidine but not for methionine. Amino-acid analysis showed that this latter peptide had the same amino-acid composition as the last 12 residues of $\alpha^{\mathrm{A}} \mathrm{T}$ pIX, while the other new peptide had the same amino-acid composition as the first 17 residues of $\alpha^{\mathrm{A}} \mathrm{TpIX}$ except that there was one aspartic residue less and a lysine residue was found instead (Table II). As this was a tryptic peptide the lysine residue must be expected to be in position 78, where an asparagine is present in the $\alpha$-chain of $\mathrm{Hb} \mathrm{A}$.
The aspartic acid residues in the control peptide from $\mathrm{Hb} \mathrm{A}$ include those formed during acid hydrolysis of the peptide from asparagine residues $\alpha 68$ and 78 . There was also a peptide present in the neutral region which was adjacent to $\beta \mathrm{TpI}$ (residues $\beta 1-8$ ) but distinguishable from it by staining positively for methionine. It is assumed that this pepticle represented $\alpha^{\mathrm{A}} \mathrm{TpVIII}$ plus residues $62-78$ of the $\alpha$-chain of Stanleyville II-that is, $\alpha$ Stanleyville TpVIII-a. From these results it can be inferred that a replacement has occurred at position $\alpha 78$ of an asparagine residue by one of lysine, and that the formula of $\mathrm{Hb}$ Stanleyville II can be written $\alpha_{2}$ Asparagine $\rightarrow$ Lysine $\beta_{2}{ }^{A}$.

The replacement occurs in a non-helical region of the $\alpha$-chain between the $\mathrm{E}$ and $\mathrm{F}$ helices (EF7), and is situated at the surface of the molecule, where it is not in contact with the haem or with any of the other haemoglobin polypeptide chains (Perutz, 1965). No pathological consequences of this mutation would therefore be expected, and indeed none haye been observed.

\section{REFERENCES}

Beale, D. (1967). Biochem. 7., 103, 129.

Dherte, P., Vanderpitte, J., Ager, J. A. M., and Lehmann, H. (1959). Brit. med. F., 2, 282.

Hall-Craggs, M., Marsden, P. D., Raper, A. B., Lehmann, H., and Beale, (D. (1964). Brit. med. . ., 2, 87.

Hill, R. J., and Konigsberg, W. (1962), \%. biol. Chem., 237, 3151.

Perutz. M. F. (1965). Y. molec. Biol., 13, 646.

Sick, K., Beale, D., Irvine, D., Lehmann, H., Goodall, P. T. and MacDougall, S. (1967). Biochim. biophys. Acta (Amst.), 140, 231 . Van Ros, G. (1966). Ann. Soc. belge Méd. trop., 46, 355.

\title{
Comparison of Piperazine and Tetramisole in Treatment of Ascariasis
}

\author{
H. C. SEFTEL,* M.B., B.CH., B.SC., DIP.MED. ; H. J. HEINZ, † PH.D.
}

Brit. med. F., 1968, 4, 93-95

\begin{abstract}
Summary : Tetramisole, a new synthetic anthelmintic, was compared with piperazine in the treatment of ascariasis in African children. Of 100 children receiving tetramisole 94 were cured, and of 100 given piperazine 85 were cured $(0.05>\mathrm{P}>0.02)$. Tetramisole was free of sideeffects.
\end{abstract}

\section{Introduction}

Tetramisole is a new synthetic anthelmintic developed by Belgian workers. Most of its properties have been summarized recently (Thienpont et al., 1966). Chemically it is the white, crystalline, stable, water-soluble hydrochloride of 2,3,5,6-tetrahydro-6-phenyl-imidazo(2,1-b)thiazole with the structure shown opposite.

\footnotetext{
- Department of Medicine, Johannesburg Non-European Hospital and Witwatersrand University, Johannesburg. † Division of Parasitology, Witwatersrand University, Johannesburg.
}

The compound is active in a number of mammalian and avian species against a variety of gastrointestinal and pulmonary nematodes such as Ascaridia, Capillaria, Heterakis, Chabertia, Bunostomum, Dictyocaulus, and Trichostrongylus. In vitro

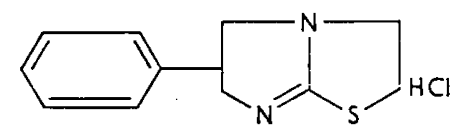

low concentrations of tetramisole exert a rapid paralysing action on nematodes which persists for many hours. The drug is inactive against cestodes, trematodes, fungi, or bacteria. It is also devoid of antihistaminic, anticholinergic, adrenolytic, or any other classical pharmacological properties. Acute and chronic toxicity studies in animals, including tests in pregnancy, have revealed a high degree of safety. The $\mathrm{LD}_{s n}$ in rats is $130 \mathrm{mg} . / \mathrm{kg}$. subcutaneously and $480 \mathrm{mg} . / \mathrm{kg}$. orally. 
The anthelmintic effect of tetramisole in man has been investigated in South America (Waks, 1965 ; Mesquita and Daher, 1966 ; Pontes and Duque, 1966 ; Nascimento et al., 1966 ; Sherb, 1966), Asia (Thienpont, 1966), and Europe (Moll, 1966 ; Janssen, 1966), and all the reports have indicated that the drug is safe and of particular value in the treatment of ascariasis. As yet, however, tetramisole has not been compared with the standard ascaris remedy, piperazine, and in this paper we report the results of such a study.

\section{Patients and Methods}

The subjects of the trial, undertaken between April and December 1967, were children attending crèches and play centres in Alexandra, an African township just outside Johannesburg. About $40 \%$ of the children were found to be infected with Ascaris lumbricoides.

Alternate cases of ascariasis, diagnosed by demonstrating ascaris eggs in faecal smears, were treated with tetramisole or piperazine. In all, 100 children received tetramisole and 100 piperazine. The age distribution of the two groups was similar. It ranged from 2 to 10 years with three-quarters of the patients between 3 and 5 years.

Both drugs were administered in single oral doses according to the following schedule: (a) Piperazine citrate (as the syrup, Antepar) $3 \mathrm{~g}$. for children weighing less than $20 \mathrm{~kg}$. and $4 \mathrm{~g}$. for those over this weight. (b) Tetramisole, in the form of small sugar-coated tablets, was used in two dosages: 69 patients received $5 \mathrm{mg} . / \mathrm{kg}$. and $312.5 \mathrm{mg}$. $/ \mathrm{kg}$. body weight. In each treatment group half the children were given the drug before breakfast and half one to two hours after. Care was taken to ensure that the drugs were actually swallowed. Purgatives were not used.

Patients were regarded as cured if stools examined two weeks after treatment were free of ascaris eggs. Such examinations were undertaken without knowing which drug the patient had been given, and the protocols were not inspected until the trial had been completed.

Side-effects were sought not only by direct observation of the children but also by questioning their parents. It was not practicable to carry out laboratory investigations for evidence of hepatic, renal, or haemopoietic toxicity on the children receiving tetramisole. Instead these were done on convalescent African adults in the medical wards of the Johannesburg NonEuropean Hospital who also happened to be suffering from ascariasis. Thirty-one patients were given tetramisole $3 \mathrm{mg}$./ $\mathrm{kg}$. body weight in a single oral dose, and the following investigations were made before and 24 to 36 hours after the dose: serum bilirubin, alkaline phosphatase, aspartate and alanine transaminases, prothrombin index, full blood count, blood urea, and chemical and microscopical examination of the urine.

\section{Results}

At the two-week follow-up examination ascaris eggs were absent from the stool in $94 \%$ of the patients treated with tetramisole and $85 \%$ of those treated with piperazine. This difference is significant $(0.05>\mathrm{P}>0.02)$. All six tetramisole failures occurred among the children who received a dose of $5 \mathrm{mg} . / \mathrm{kg}$. bodyweight ; two had been given the drug before breakfast and four after. Of the 15 piperazine failures nine had received the drug before and six after breakfast.

It was not possible to compare accurately the manner, timing, and number of worms expelled after administration of the two drugs, but the pattern appeared to be similar. The worms were expelled, immobilized and intact, usually within 24 hours, but the occasional patient continued to pass ascarides for two to three days. The number of worms expelled varied between 1 and 60 , but was most commonly between 4 and 12 .

The children took the two preparations equally well, and the only side-effect noted was vomiting, which occurred in two children within an hour of being given piperazine. No abnormalities were detected in the laboratory tests carried out on the adult patients.

\section{Discussion}

In this trial, using single oral doses, with or without fasting, and without purging, tetramisole was marginally more effective than piperazine in the treatment of ascariasis in African children. The drug appeared to be equally effective at dosages of 2.5 and $5 \mathrm{mg} . / \mathrm{kg}$. body weight, which is in keeping with the reports of Sherb (1966) and Mesquita and Daher (1966), who cured more than $90 \%$ of cases with a single dose of 2 to 2.5 mg./kg. Rodrigues et al. (1966), using the cyclamate salt of tetramisole in single doses of $5 \mathrm{mg} . / \mathrm{kg}$., cured $88 \%$ of 49 cases; of 12 patients who had previously failed to respond to piperazine 11 were cured with tetramisole. On the other hand, Nascimento et al. (1966) cured only $53 \%$ of sufferers with 3 to $4 \mathrm{mg}$. $/ \mathrm{kg}$., and doses of 5 to $8 \mathrm{mg} . / \mathrm{kg}$. were needed to achieve a recovery rate of 80 to $90 \%$.

The tetramisole tablets were simple to administer, and in the dosages used here side-effects were not observed. It is obvious, however, that because of the age of our subjects adverse reactions may have gone undetected. Those noted by other workers include nausea, vomiting, abdominal pain, diarrhoea, malaise, giddiness, and drowsiness. They were usually mild and transient, and appeared to be dose-dependent, occurring largely in patients receiving more than 4 to $5 \mathrm{mg} . / \mathrm{kg}$. Nascimento et al. (1966) noted that nausea and vomiting did not occur in children who were given the drug after meals. Like ourselves, other workers (Waks, 1965 ; Janssen, 1966 ; Nascimento et al., 1966 ; Mesquita and Daher, 1966 ; Pontes and Duque, 1966 ; Sherb, 1966) have found therapeutic doses of tetramisole to be free of hepatic, renal, or haemopoietic toxicity. Like piperazine, tetramisole results in the expulsion of paralysed and intact worms, thereby reducing the hazards of migrating ascarides and toxic or allergic reactions to the products of disintegrating parasites.

All present remedies for ascariasis fall short of the ideal of $100 \%$ efficacy in all grades of infection when used in single oral doses without fasting or purging, and freedom from sideeffects. Thus single doses of piperazine, the current drug of choice, may be curative in less than $60 \%$ of heavily infected patients (Fields et al., 1956 ; Brown, 1960). To what extent tetramisole approaches the ideal it is still too early to say. Larger doses might be more effective but would probably produce more side-effects. Alternatively, it might be worth trying the laevorotatory isomer of tetramisole, which experimentally is twice as active but just as safe as the racemic compound used in this trial (Van den Bossche and Janssen, 1967). Finally, there is good evidence that tetramisole paralyses ascaris muscle by inhibiting the production of succinate (Van den Bossche and Janssen, 1967). Piperazine also reduces succinate formation as well as blocking the response of ascaris muscle to acetylcholine (Bueding and Swartzwelder, 1957). It is therefore possible that a combination of the two drugs may have a synergistic effect against the parasite without producing a corresponding increase in side-effects in the host.

We wish to thank Mrs. D. Mabiletsa, Director of the Entokozwen Family Welfare Centre, Alexandra, for permission to study the children under her care; Professor J. H. S. Gear, Director of the South African Institute for Medical Research which undertook the haematological, hepatic, and renal investigations; and Dr. R. E. Bauling, Medical Director of Ethnor (Pty) Ltd., for supplies of tetramisole and much helpful advice. 
REFERENCES

Brown, H. W. (1960). Clin. Pharmacol. Then, 1, 87.

Bueding, E., and Swartzwelder, C. (1957). Pharmacol. Rev., 9, 329. Fields, D N.,, Selly, G. W., and Guicherit, I. D. (1956). Docum. Med. geogr. trop. (Amst.), 8, 80.

Janssen, E. G. (1966). Personal communication.

Mesquita, P. M., and Daher, H. R. (1966). Hospizal (Rio de 7.), 69, 1279 .

Moll, R. (1966). Personal communication.

Nascimento Filha, O. B. do, Halsman, M., Oria, H., and Campos, J. V. M. (1966). Rev. Inst. Med. trop. S. Paulo, 8, 143.
Pontes, J. F., and Duque, A. F. (1966). Personal communication. Rodrigues, L. D., Vilela, M. de P., and Capell, J. I. (1966). Rev. bras. Med., 23, 861.

Sherb, J. (1966). Thesis for Doctorate on "The Effects of Tetramisole in the Treatment of Ascariasis," Pernambuco University, Roctfe, Brazil.

Thienpont, D. (1966). Personal communication.

Thienpont, D., et al. (1966). Nature (Lond.), 209, 1084.

Van den Bossche, H., and Janssen, P. A. J. (1967). Life Sci., 6, 1781.

Waks, J. (1965). Personal communication.

\section{Preliminary Communications}

\section{Studies of Small-intestinal Mucosa with the Scanning Electron Microscope}

\author{
[With Special Plate]
}

Brit. med. F., 1968, 4, 95-96

Summary : Preliminary observations indicate that scanning electron microscopy is a useful method for studying the surface of the small intestine.

\section{INTRODUCTION}

The development of a commercial scanning electron microscope (Stereoscan, Cambridge Instrument Company, Cambridge, England) has made possible direct examination of the mucosal surface of the human small intestine. With this method large pieces of tissue up to $12 \mathrm{~mm}$. in diameter may be examined rapidly at low and high magnifications (from $\times 20$ to $\times 10,000$ ). Resolutions of the order of 0.05 micron $(\mu)$ are obtained, permitting ready identification of microvilli, and great depths of focus may be achieved, so that parts of the specimen at different levels are clearly focused. The depth of focus of the scanning electron microscope is at least $\mathbf{3 0 0}$ times that of the optical microscope. Specimens may be viewed in almost any orientation. Indeed, by tilting the specimen, stereo-pair electron micrographs may be obtained, facilitating the interpretation of surface topography.

In this preliminary report we describe the scanning electron microscope appearances of the jejunum in normal subjects and in those with adult coeliac disease.

\section{MethoDS}

Fresh jejunal mucosa was obtained either at laparotomy from four control subjects or by biopsy capsule (Crosby and Kugler, 1957) located just beyond the duodenojejunal flexure in two individuals with adult coeliac disease. The specimens were orientated, carefully pinned out, and washed with normal saline. They were fixed in $5 \%$ glutaraldehyde (buffered with $0.1 \mathrm{M}$ phosphate at $\mathrm{pH}$ 6.8) for four hours at $4^{\circ} \mathrm{C}$., then washed and stored in $0.1 \mathrm{M}$ phosphate buffer, $\mathrm{pH} 6.8$ (containing $0.1 \mathrm{M}$ sucrose), at $4^{\circ} \mathrm{C}$. until required.

Specimens were subsequently washed in three changes of distilled water at $4^{\circ} \mathrm{C}$. and then rapidly frozen in liquid $\mathbf{N}_{2}$ cooled Arcton 12 for 30 seconds before transfer to the previously cooled stage of a Speedivac-Pearse vacuum tissue drier. Tissue was freeze-dried for 18 hours at $-50^{\circ} \mathrm{C}$. and then placed in clean glass bottles containing anhydrous calcium chloride until ready for vacuum-coating with metal.
The freeze-dried specimens were glued with Durofix to small 12-mm. diameter aluminium mounting stubs and coated with a layer of carbon about $100 \AA$ thick and then with a layer of silver about $500 \AA$ thick in an Edwards $12 \mathrm{E} 6$ vacuum-coating unit, the specimens being rapidly rotated during this process.

The coated specimens were examined directly in a Cambridge Stereoscan Mk II scanning electron microscope operated at an accelerating potential of $20 \mathrm{kV}$. Photographs of the specimen were recorded from the 1,000 line television display screen of the microscope on Ilford $35-\mathrm{mm}$. FP3 film.

\section{CONTrol SMall INTESTINB}

The majority of villi of small intestine from control subjects appeared as finger-shaped projections of about $0.12 \mathrm{~mm}$. diameter (Special Plate, Fig. 1). Occasionally leaf-shaped villi about $0.1 \mathrm{~mm}$. thick and up to $1 \mathrm{~mm}$. long were observed.

The surface of each villus was broken up by numerous transverse corrugations and pitted with several small holes approximately 5-6 $\mu$ in diameter, some of which were connected by shallow furrows (Special Plate, Fig. 2). These holes may represent the orifices of underlying goblet cells.

At higher magnifications the villus surfaces were partly covered by strands and irregular blobs of mucus. In areas where mucus was absent relatively well organized arrays of tiny nodules (about $0.1-0.15 \mu$ diameter) were seen. These appear to be the tips of the microvilli (Special Plate, Fig. 3), for their dimensions correspond to those of microvilli seen in transmission electron micrographs of sectioned intestine (Fawcett, 1966).

\section{Adult Coeliac Disease}

In general, the appearances of the mucosal surface were strikingly different from the normal. There was also marked variability in the surface morphology between adjacent areas ; no particular area could be taken as wholly representative.

At low magnifications, short, stubby, and relatively flat-topped villi could be recognized whose surface consisted of closepacked, almost hemispherical projections (Special Plate, Fig. 4). However, in other areas the surface was flatter and deeply creviced (Special Plate, Fig. 5) and irregularly studded with similar hemispherical projections.

At intermediate and higher magnifications (Special Plate, Figs. 6 and 7) the surface of these hemispherical projections was covered with smaller projections of 6-8 $\mu$ diameter which were taken to represent epithelial cells. In some areas these cells had a somewhat blurred granular surface structure (Fig. 6) while in 